\title{
Complete remission of paraneoplastic vanishing bile duct syndrome after the successful treatment of Hodgkin's lymphoma: a case report and review of the literature
}

Delia Rota Scalabrini', Daniela Caravelli', Fabrizio Carnevale Schianca', Lorenzo D'Ambrosio ${ }^{1}$, Francesco Tolomeo ${ }^{1}$, Paola Boccone, Antonio Manca², Giovanni De Rosa ${ }^{3}$, Annamaria Nuzzo ${ }^{1}$, Massimo Aglietta'

and Giovanni Grignani ${ }^{*}$

\begin{abstract}
Background: Vanishing bile duct syndrome has been associated with different pathologic conditions (adverse drug reactions, autoimmune diseases, graft versus host disease, and cancer). Though its causes are unknown, an immune-related pathogenesis is the most likely one. Vanishing bile duct syndrome can evolve to hepatic failure and, eventually, to death. The treatment is uncertain, but it needs the resolution of the underlying pathologic condition.

Case presentation: We describe the association of Hodgkin's lymphoma with a syndrome characterized by cholestasis, aminotransferase elevation and an histological picture of bile duct loss. All other causes of hepatic function impairment were excluded (in particular, drugs, viral and autoimmune related diseases) eventually leading to the diagnosis of vanishing bile duct syndrome. Despite the fact that the dysfunction is not caused by hepatic Hodgkin's lymphoma involvement, liver impairment can limit the optimal therapy of Hodgkin's lymphoma. A treatment consisting of ursodeoxycholic acid, prednisone, and full dose chemotherapy restored hepatic function and achieved complete and long-lasting remission of Hodgkin's lymphoma.

Conclusion: We reviewed all case reports showing that vanishing bile duct syndrome is a dismal paraneoplastic syndrome being fatal in a high proportion of patients if not adequately treated. Indeed, this syndrome requires both an early recognition and an appropriate aggressive treatment consisting of full dose upfront chemotherapy which is the only way to achieve a resolution of the vanishing bile duct syndrome. Delayed or reduced intensity treatments unfavorably correlate with survival.
\end{abstract}

Keywords: Vanishing bile duct syndrome, Ductopenia, Hodgkin's lymphoma, Ursodeoxycholic acid, Paraneoplastic syndrome

\section{Background}

Vanishing bile duct syndrome (VBDS) is defined as an intrahepatic cholestasis with paucity of interlobular bile ducts [1]. The cause is unknown and it has been associated with different pathologic conditions: adverse drug reactions, autoimmune diseases, graft versus host disease, and cancer. These associations make the immune-mediated

\footnotetext{
* Correspondence: giovanni.grignani@ircc.it

'Division of Oncology, Candiolo Cancer Institute, FPO, IRCCS, University of

Torino Medical School, Candiolo, Italy
}

Full list of author information is available at the end of the article pathogenesis the most likely one. Histology is characterized by marked cholestasis without evidences of an accompanying hepatitis, but with a characteristic loss of bile ducts in the portal tracts. Clinical outcome is hepatic failure unless the underlying disease can be appropriately cured. We present a case of a VBDS that heralded the successive diagnosis of Hodgkin's lymphoma (HL).

\section{Case presentation}

A 42-year-old Caucasian woman was admitted to an infectious disease unit because of jaundice and fever. Her 
medical past history was unremarkable except for a mild allergy to cat hair. On admission her abnormal chemical tests were: total and direct bilirubin of 18.3 milligrams/ deciliter $(\mathrm{mg} / \mathrm{dL}$ ) and $15.3 \mathrm{mg} / \mathrm{dL}$, respectively (normal value up to 1.3 and $0.4 \mathrm{mg} / \mathrm{dL}$, respectively); aspartate (AST) and alanine aminotransferase (ALT), 151 and 322, respectively (normal value up to 35 units/liter (U/L) and $40 \mathrm{U} / \mathrm{L}$, respectively); alkaline phosphatase (ALP) $322 \mathrm{U} / \mathrm{L}$ (normal value up to $240 \mathrm{U} / \mathrm{L}$ ); gamma-glutamyl transpeptidase (GGT) $482 \mathrm{U} / \mathrm{L}$ (normal value up to $35 \mathrm{U} / \mathrm{L}$ ). Blood counts were normal except for leukocytosis $(15170 / \mu \mathrm{L})$. The patient was not taking any drug, and an extensive infectious disease work-up was negative. Particularly, hepatotropic viruses such as hepatitis A virus (HAV), hepatitis $\mathrm{B}$ virus $(\mathrm{HBV})$ and hepatitis $\mathrm{C}$ virus $(\mathrm{HCV})$ were excluded as well as Epstein-Barr virus (EBV) and cytomegalovirus (CMV). A computed tomography (CT) scan showed enlarged mediastinal lymph nodes without any abdominal pathological feature, and no sign of biliary tract dilatation. At that time, the patient was referred to our center, and a mediastinal biopsy was performed showing a picture of classic HL of nodular sclerosis histotype. Furthermore, the most common antibodies responsible for autoimmune hepatitis (ANA - antinuclear antibodies, ASMA - antismooth-muscle antibodies, anti-LKM1 - anti-liverkidney microsomal type 1, anti-SLA - antibodies against soluble liver antigen, AMA - antimitochondrial antibody, antiphospholipid antibodies) were evaluated without any pathological findings. Since biochemical cholestasis had worsened (total bilirubin $33.8 \mathrm{mg} / \mathrm{dL}$ ), a hepatic biopsy was performed showing marked cellular and canalicular perivenous cholestasis. Remarkably, bile ducts were absent (Figure 1) in all seven portal tracts examined and no sign of HL could be detected in a picture consistent with a VBDS [1]. Bone marrow trephine was negative. We also carried out a positron emission tomography (PET) scan that showed increased 18 F-fluoro-deoxy-glucose (18 F-FDG) uptake in multiple mediastinal lymph nodes defining a stage IIB HL. She was started on ursodeoxycholic acid (UDCA) (1350 mg daily) and prednisone (50 mg daily). A dramatic improvement of her clinical and biochemical conditions occurred with a decreased total bilirubin to $10 \mathrm{mg} /$ $\mathrm{dL}$. At this point, doxorubicin, bleomycin, vinblastine and dacarbazine (ABVD) chemotherapy was delivered and, after 4 cycles, we performed interim restaging with the PET scan showing a complete response. Therefore, she subsequently received two additional cycles of ABVD with a complete response confirmed after six cycles. Despite the fact that total bilirubin was increased at the time of the first cycle, we delivered a full dose of doxorubicin and vinblastine. At completion, prednisone was tapered and UDCA interrupted. The patient declined to receive a hepatic biopsy at the end of chemotherapy. Six years later, she is still in complete remission with a thoroughly normal hepatic function.

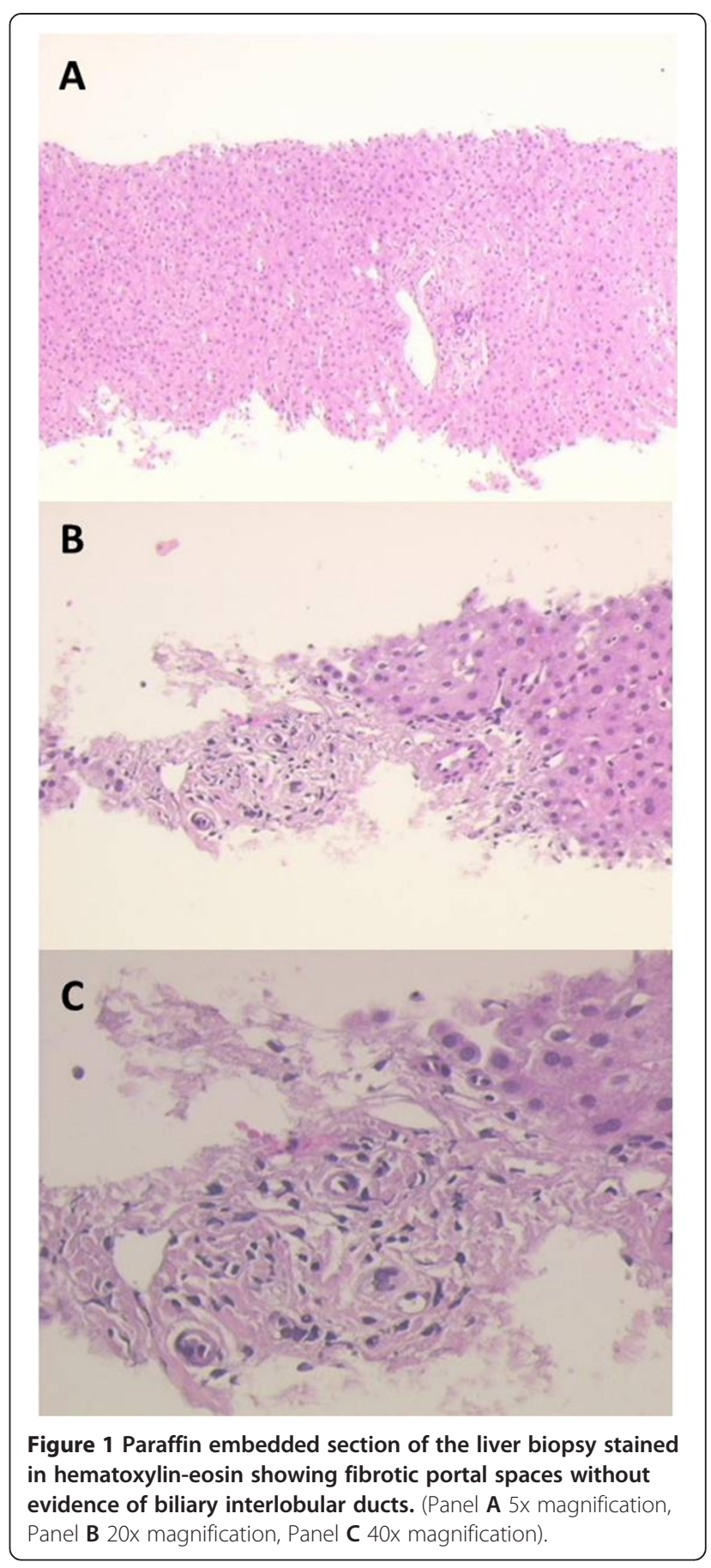

\section{Conclusion}

Several conditions may cause jaundice in HL. Biliary obstruction secondary to lymph nodes enlargement, hemolysis, hepatotropic and other viruses (e.g. CMV) are among the most common causes. Hepatic direct involvement by HL is a relatively rare, but well known complication [2]. The association of cholestatic jaundice and hepatic bile duct loss (a picture called "ductopenia") in HL has been described in other 39 other cases in the literature (Table 1). This is a 
Table 1 Summary of all cases reported in the literature regarding vanishing bile duct syndrome in lymphomas

\begin{tabular}{|c|c|c|c|c|c|}
\hline Author & $\begin{array}{c}\text { Number of } \\
\text { patients }\end{array}$ & $\begin{array}{c}\text { Hodgkin lymphoma } \\
\text { treatment* }\end{array}$ & Dosage & Ursodeoxycholic acid & Outcome \\
\hline \multirow[t]{2}{*}{ Bouroncle B. [9] } & 2 & Yes & Full & Unknown & Hepatic failure \\
\hline & & Yes & Reduced & & Hepatic failure \\
\hline Juniper K. [10] & 1 & Yes & Reduced & Unknown & Hepatic failure \\
\hline Groth C. [11] & 1 & Yes & Full & Unknown & Hepatic failure \\
\hline \multirow[t]{3}{*}{ Perera D.R. [12] } & 3 & Yes & Full & Unknown & Hepatic failure \\
\hline & & Yes & Full & Unknown & Cure \\
\hline & & Yes & Full & Unknown & Cure \\
\hline Piken E.P. [13] & 1 & Yes & Full & Unknown & Unknown \\
\hline \multirow[t]{4}{*}{ Trewby P.N. [14] } & 4 & Yes & Full & Unknown & Cure \\
\hline & & Yes & Full & Unknown & Cure \\
\hline & & Yes & Full & Unknown & Unknown \\
\hline & & No & No & Unknown & Unknown \\
\hline Lieberman D.A. [15] & 1 & No & No & No & Respiratory arrest \\
\hline Birrer M.J. [16] & 1 & Yes & Full & Unknown & Sepsis \\
\hline Hubscher S.G. [1] & 3 & Yes & Reduced & No & Hepatic failure \\
\hline Jansen P.L.M. [17] & 1 & Yes & Full & Late & Hepatic failure \\
\hline Warner A.S. [18] & 1 & Yes & Full & No & Cure \\
\hline Gottrand F. [19] & 1 & No & No & No & Hepatic failure \\
\hline Crosbie O.M. [20] & 1 & Yes & Full & Yes & Cure \\
\hline \multirow[t]{2}{*}{ De Medeiros B.C. [21] } & 2 & Yes & Full & No & Hepatic failure \\
\hline & & & Full & & \\
\hline \multirow[t]{2}{*}{ Yalcin S. [22] } & 2 & No & No & No & Hepatic failure \\
\hline & & Yes & Full & No & Cure \\
\hline Dourakis S.P. [23] & 1 & Yes & Reduced & No & Hepatic failure \\
\hline Yusuf M.A. [24] & 1 & No & No & Late & Hepatic failure \\
\hline Rossini M.S. [25] & 1 & Yes & Full & No & Hepatic failure \\
\hline Allory Y. [3] & 1 & Yes & Full & Yes & Cure \\
\hline Ozkan A. [26] & 1 & No & No & Late & Hepatic failure \\
\hline \multirow[t]{2}{*}{ Ripoll C. [27] } & 2 & Yes & Full & No & Hepatic failure \\
\hline & & Yes & Full & Yes & Cure \\
\hline Komurcu S. [28] & 1 & Yes & Full & No & Hepatic failure \\
\hline Liangpunsakul S. [29] & 1 & Yes & Full & No & Cure \\
\hline Guliter S. [30] & 1 & Yes & Full & Late & Hepatic failure \\
\hline Córdoba Iturriagagoitia A. [31] & 1 & Yes & Full & No & Cure \\
\hline Han W.S. [32] & 1 & No & No & No & Recurrent Hodgkin's Lymphoma \\
\hline Schmitt A. [33] & 1 & No & No & No & Hepatic failure \\
\hline Barta S.K. [34] & 1 & Yes & Full & No & Cure \\
\hline DeBenedet A.T. [35] & 1 & Yes & Reduced & No & Hepatic failure \\
\hline Leeuwenburgh I. [36] & 1 & Yes & Reduced & No & Cure \\
\hline \multirow[t]{2}{*}{ Pass A.K. [37] } & 2 & Yes & Reduced & Yes & Cure \\
\hline & & Yes & Reduced & No & Hepatic failure \\
\hline Ballonoff A. [38] & 1 & Yes & Full & No & Cure \\
\hline Umit H. [39] & 1 & Unknown & Unknown & Unknown & Unknown \\
\hline
\end{tabular}


Table 1 Summary of all cases reported in the literature regarding vanishing bile duct syndrome in lymphomas (Continued)

\begin{tabular}{|c|c|c|c|c|c|}
\hline Gill R.M. [40] & 1 & Yes & Reduced & No & Hepatic failure \\
\hline Foramiti S. [41] & 1 & Yes & Full & Yes & Hepatic failure \\
\hline Gagnon MF [42] & 1 & Yes & Full & No & Cure \\
\hline Wong KM [43] & 1 & Yes & Full & No & Cure \\
\hline Aleem A1 [44] & 1 & Yes & Full & No & Hepatic failure \\
\hline Nader K [45] & 1 & Yes & Full & No & Hepatic failure \\
\hline Our patient & 1 & Yes & Full & Yes & Cure \\
\hline
\end{tabular}

*either chemotherapy or radiotherapy.

severe complication with a high rate of death in a neoplastic disease otherwise curable in more than $80 \%$ of patients. In $18 \mathrm{HL}$ patients steroid plus lymphoma treatment (both chemotherapy and radiotherapy) was described to improve hepatic function and eventually led to complete remission of both hepatic and Hodgkin's diseases. All other cases died because of hepatic failure. A clear pathogenetic relationship between HL and VBDS cannot be identified. Nevertheless, the concomitance of the two diseases and the case reported by Allory [3] makes the hypothesis of VBDS likely to be a paraneoplastic manifestation of HL. Furthermore, Bruguera [4] has shown hepatic sinusoidal dilatation (a feature of VBDS) in $90 \%$ of patients presenting systemic symptoms (so called B symptoms) without any evidence of direct liver involvement by the lymphoma. This datum suggests the role of $\mathrm{HL}$ as the trigger event of cytokine-mediated hepatic damage [5]. There is evidence that biliary epithelial cells [6] express major histocompatibility complex (MHC) antigens (both class I and II) as well as adhesion molecules like intercellular adhesion molecule 1 (ICAM-1) in response to cytokines produced by HL. In this context, both types of molecules may contribute to adhesion and cytotoxicity due to $\mathrm{T}$ lymphocytes. As of today, there is no recognized treatment for VBDS. We, as well as other authors, used UDCA because of its demonstrated activity in primary biliary cirrhosis. Indeed, beneficial effects of treatment with UDCA have been reported in other immune-mediated disease involving the biliary tree as primary sclerosing cholangitis [7] or hepatic involvement by graft versus host disease [8]. UDCA acts at three levels: increasing the expression of transporter proteins into the canalicular membrane, inhibiting apoptosis induced by toxic bile acids, and altering the composition of the micelles of bile acids [7].

In the present report we stress two aspects. First, the therapeutic choice to use high-dose of UDCA [46] and prednisone which rapidly determined an improvement of our patients. Secondly, although still icteric, we delivered a full dose chemotherapy achieving a sustained complete remission that, in a paraneoplastic disease, is the most important result. An appropriate aggressive treatment (either chemotherapy or radiotherapy) was reported in all patients who were, in the end, cured (Table 1). Notwithstanding, several good reasons stand for a dose reduction in both doxorubicin and vinblastine in a jaundiced patient, we emphasize the "full dose" chemotherapy choice. ABVD chemotherapy is conceived as a 2weekly treatment and, therefore, $25 \mathrm{mg} / \mathrm{m}^{2}$ doxorubicin was felt appropriate regardless of jaundice. Indeed, it is half the dose used in other combinations (e.g. CHOP regimen Cyclophosphamide, Doxorubicin, Vincristine, Prednisone or CODOX-M/IVAC - Cyclophosphamide, Vincristine, Doxorubicin, Methotrexate, Ifosfamide, Etoposide, Cytarabine $[47,48])$. Moreover, it is well known that the ABVD dose intensity affects the HL outcome [49,50]. Lastly, only 1 out of $8(12 \%)$ patients receiving an upfront reduced chemotherapy overcame the vanishing bile duct, compared to $51 \%(17 / 33)$ of patients treated with upfront full dose chemotherapy (see Table 1). In these patients the efficacious treatment of the lymphoma preceded the hepatic improvement and, ultimately, the cure.

This case report demonstrates that in the presence of a histological diagnosis of HL associated with signs of cholestasis and liver function impairment without gross liver involvement or biliary tract dilatation, the prompt treatment of the underlying disease in association with high doses of UDCA is crucial. Indeed, data available in the literature strengthen the theory that the therapy able to restore liver function is full dose chemotherapy only. In this setting, waiting for the histological confirmation of VBDS may be harmful because a delayed start might be detrimental to patient outcome. Indeed, liver impairment could evolve to liver insufficiency and eventually to death as is clearly outlined in Table 1 .

In conclusion, VBDS must be considered a rare but possible complication of HL. Its prompt recognition and appropriate treatment can dramatically affect patients' outcome.

\section{Consent}

Written informed consent was obtained from the patient for publication of this Case Report and any accompanying images. A copy of the written consent is available for review by the Editor-in-Chief of this journal. 


\section{Competing interests}

All authors declared no competing interests.

\section{Authors' contributions}

DRS, DC, FCS, LD, FT, PB, AN, MA, GG were involved in the differential diagnosis of VBDS, in the clinical care of the patient and in the data collection and report. AM performed the biopsies. GD performed the histological diagnoses. All authors revised the manuscript and approved the final version for submission.

\section{Acknowledgements}

All authors acknowledge the nurses who helped in the clinical care of this patient. We thank Ms Elisa De Boni and Ms Hannah Gregory for language editing. None of the authors received funding for writing this article.

\section{Author details}

${ }^{1}$ Division of Oncology, Candiolo Cancer Institute, FPO, IRCCS, University of Torino Medical School, Candiolo, Italy. ${ }^{2}$ Radiology Unit, Candiolo Cancer Institute, FPO, IRCCS, Candiolo, Italy. 'Division of Surgical Pathology, Ospedale Umberto I Ordine Mauriziano, Torino, Italy.

Received: 26 February 2014 Accepted: 4 August 2014

Published: 14 August 2014

\section{References}

1. Hubscher SG, Lumley MA, Elias E: Vanishing bile duct syndrome: a possible mechanism for intrahepatic cholestasis in Hodgkin's lymphoma. Hepatology 1993, 17:70-77.

2. Cervantes F, Briones J, Bruguera M, Font C, Grau JM, Rozman C, Montserrat E: Hodgkin's disease presenting as cholestatic febrile illness and main characteristics in a series of 421 patients. Ann Hematol 1996, 72:357-360

3. Allory $Y$, Metreu J, Zafrani E: Paraneoplastic vanishing bile duct syndrome in a case of Hodgkin's disease. Ann Pathol 2000, 20:52-55.

4. Bruguera M, Caballero T, Carreras E, Aymerich M, Rodes J, Rozman C: Hepatic sinusoidal dilatation in Hodgkin's disease. Liver 1987, 7:76-80.

5. Reynoso-Paz S, Coppel RL, Ansari AA, Gershwin ME: Vanishing bile duct syndromes: considerations of the immuno-biology of autoimmune biliary diseases. IMAJ 1999, 1:37-48.

6. Adams DH, Hubscher SG, Shaw J, Rothlein R, Neuberger JM: Intercellular adhesion molecule 1 on liver allografts during rejection. Lancet 1989, 2:1122-1125.

7. Pusl T, Beuers U: Ursodexycholic acid treatment of vanishing bile duct syndromes. World J Gastroenterol 2006, 12:3487-3495.

8. Fried RH, Murakami CS, Fisher LD, Willson RA, Sullivan KM, McDonald GB: Ursodeoxycholic acid treatment of refractory chronic graft-versus-host disease of the liver. Ann Intern Med 1992, 116:624-629.

9. Bouroncle BA, Old J, Vazques AG: Pathogenesis of jaundice in Hodgkin's disease. Arch Intern Med 1962, 110:872-883.

10. Juniper $\mathrm{K} \mathrm{Jr}$ : Prolonged severe obstructive jaundice in Hodgkin's disease. Gastroenterology 1963, 44:199-204.

11. Groth CG, Hellström K, Hofvendahl S, Nordenstam H, Wengle B: Diagnosis of malignant lymphoma at laparotomy disclosing intrahepatic cholestasis. Acta Chir Scand 1972, 138:186-189.

12. Perera DR, Greene MJ, Fenster LF: Cholestasis associated with extrabiliary Hodgkin's disease. Gastroenterology 1974, 67:680-685.

13. Piken EP, Abaraham GE, Hepner GW: Investigation of a patient with Hodgkin's disease and cholestasis. Gastroenterology 1979, 77:145-147.

14. Trewby PN, Portmann B, Brinkley DM, Williams R: Liver disease as presenting manifestation of Hodgkin's disease. Q J Med 1979, 48:137-150.

15. Lieberman DA: Intrahepatic cholestasis due to Hodgkin's disease: an elusive diagnosis. J Clin Gastroenterol 1986, 8:304-307.

16. Birrer MJ, Young RC: Differential diagnosis of jaundice in lymphoma patients. Semin Liver Dis 1987, 7:269-277.

17. Jansen $\mathrm{PL}$, van der Lelie $\mathrm{H}$ : Intrahepatic cholestasis and biliary cirrhosis associated with Hodgkin's disease. Neth J Med 1994, 44:99-102.

18. Warner AS, Whitcomb FF: Extrahepatic Hodgkin's disease and cholestasis. Am J Gastroenterol 1994, 89:940-941.

19. Gottrand F, Cullu F, Mazingue F, Nelken B, Lecomte-Houcke M, Farriaux JP: Intrahepatic cholestasis related to vanishing bile duct syndrome in Hodgkin's disease. J Pediatr Gastroenterol Nutr 1997, 24:430-433.
20. Crosbie OM, Crown JP, Nolan NPM, Murray R, Hegarty JE: Resolution of paraneoplastic bile duct paucity following successful treatment of Hodgkin's disease. Hepatology 1997, 26:5-8.

21. de Medeiros BC, Lacerda MA, Telles JEQ, da Silva JAS, de Medeiros CS: Cholestasis secondary to Hodgkin's disease: report of 2 cases of vanishing bile duct syndrome. Haematologica 1998, 83:1038-1040.

22. Yalcin S, Kars A, Sokmensuer C, Atahan L: Extrahepatic Hodgkin's disease with intrahepatic cholestasis: report of two cases. Oncology 1999, 57:83-85.

23. Dourakis SP, Tzemanachis E, Deutsch M, Kafiri G, Hadziyannis SJ: Fulminant hepatic failure as presenting paraneoplastic manifestation of Hodgkin's disease. Eur J Gastroenterol Hepatol 1999, 11:1055-1058.

24. Yusuf MA, Elias E, Hubscher SG: Jaundice caused by the vanishing bile duct syndrome in a child with Hodgkin's lymphoma. J Pediatr Hemato Oncol 2000, 22:154-157.

25. Rossini MS, Lorand-Metze I, Oliveira GB, De Souza CA: Vanishing bile duct syndrome in Hodgkin's disease: case report. Sao Paulo Med J 2000, 118:154-157.

26. Ozkan A, Yoruk A, Celkan T, Apak H, Yildiz I, Ozbay G: The vanishing bile duct syndrome in a child with Hodgkin's disease. Med Pediatr Oncol 2001, 36:398-399.

27. Ripoll C, Carretero L, Sabir P, Alvarez E, Marrupe D, Banares R: Idiopathic cholestasis associated with progressive ductopenia in two patients with Hodgkin's disease. Gastroenterol Hepatol 2002, 25:313-315.

28. Kömürcü S, Ozet A, Altundag MK, Arpaci F, Oztürk B, Celasun B, Tezcan Y: Vanishing bile duct syndrome occurring after high-dose chemotherapy and autologous peripheral stem cell transplantation in a patient with Hodgkin's disease. Ann Hematol 2002, 81:57-58.

29. Liangpunsakul S, Kwo P, Koukoulis GK: Hodgkin's disease presenting as cholestatic hepatitis with prominent ductal injury. Eur J Gastroenterol Hepatol 2002, 14:323-327.

30. Guliter S, Erdem O, Isik M, Yamac K, Uluoglu O: Cholestatic liver disease with ductopenia (vanishing bile duct syndrome) in Hodgkin's disease: report of a case. Tumori 2004, 90:517-520.

31. Cordoba Iturriagagoitia A, Inarrairaegui Bastarrica M, Perez de Equiza E, Zozaya Urmeneta JM, Martinez-Penuela JM, Beloqui Perez R: Ductal regeneration in vanishing bile duct syndrome in Hodgkin's lymphoma. Gastroenterol Hepatol 2005, 28:275-278.

32. Han WS, Jung ES, Kim YH, Kim CH, Park SC, Lee JY, Chang YJ, Yeon JE, Byun $\mathrm{KS}$, Lee CH: Spontaneous resolution of vanishing bile duct syndrome in Hodgkin's lymphoma. Korean J Hepatol 2005, 11:164-168.

33. Schmitt A, Gilden DJ, Saint S, Moseley RH: Clinical problem-solving. Empirically incorrect. N Engl J Med 2006, 354:509-514.

34. Barta SK, Yahalom J, Shia J, Hamlin PA: Idiopathic cholestasis as a paraneoplastic phenomenon in Hodgkin's lymphoma. Clin Lymphoma Myeloma 2006, 7:77-82.

35. DeBenedet AT, Berg CL, Enfield KB, Woodford RL, Bennett AK, Northup PG: A case of vanishing bile duct syndrome and IBD secondary to Hodgkin's lymphoma. Nat Clin Pract Gastroenterol Hepatol 2008, 5:49-53.

36. Leeuwenburgh I, Lugtenburg EP, van Buuren HR, Zondervan PE, de Man RA: Severe jaundice, due to vanishing bile duct syndrome, as presenting symptom of Hodgkin's lymphoma, fully reversible after chemotherapy. Eur J Gastroenterol Hepatol 2008, 20:145-147.

37. Pass AK, McLin VA, Rushton JR, Kearney DL, Hastings CA, Margolin JF: Vanishing bile duct syndrome and Hodgkin disease: a case series and review of the literature. J Pediatr Hematol Oncol 2008, 30:976-980.

38. Ballonoff A, Kavanagh B, Nash R, Drabkin H, Trotter J, Costa L, Rabinovitch R: Hodgkin lymphoma-related vanishing bile duct syndrome and idiopathic cholestasis: statistical analysis of all published cases and literature review. Acta Oncol 2008, 47:962-970.

39. Umit H, Unsal G, Tezel A, Soylu AR, Pamuk GE, Turgut B, Demir M, Tucer D, Ermantas N, Cevikbas U: Vanishing bile duct syndrome in a patient with Hodgkin's lymphoma and asymptomatic hepatitis B virus infection. Acta Gastroenterol Belg 2009, 72:277-278.

40. Gill RM, Ferrell LD: Vanishing bile duct syndrome associated with peripheral $\mathrm{T}$ cell lymphoma, not otherwise specified, arising in a posttransplant setting. Hepatology 2010, 51:1856-1857.

41. Foramiti S, Biondini E, Bigolin T, Pasca S, Rossi P: Vanishing bile duct syndrome in non-Hodgkin lymphoma: a case report. Minerva Med 2011, 102:345-349.

42. Gagnon MF, Nguyen BN, Olney HJ, Lemieux B: Vanishing bile duct syndrome arising in a patient with T-cell-rich large B-cell lymphoma. J Clin Oncol 2013, 31:e357-e359. 
43. Wong KM, Chang CS, Wu CC, Yin HL: Hodgkin's lymphoma-related vanishing bile duct syndrome: a case report and literature review. Kaohsiung J Med Sci 2013, 29:636-641.

44. Aleem A, Al-Katari M, Alsaleh K, Alswat K, Al-Sheikh A: Vanishing bile duct syndrome in a hodgkin's lymphoma patient with fatal outcome despite lymphoma remission. Saudi J Gastroenterol 2013, 19:286-289.

45. Nader K, Mok S, Kalra A, Harb A, Schwarting R, Ferber A: Vanishing bile duct syndrome as a manifestation of Hodgkin's lymphoma: a case report and review of the literature. Tumori 2013, 99:164e-168e.

46. Moreno A, Careno V, Cano A, Gonzalez C: Idiopathic biliary ductopenia in adults without symptoms of liver disease. N Eng J Med 1997, 336:835-838.

47. Fanale MA, Lai C-M, McLaughlin P, Romaguera JE, Fayad L, Hagemeister FB, Samaniego F, Rodriguez MA, Neelapu SS, Shah JJ, Kwak L, Dong W, Reed V, Dabaja BS, Popat UR, Younes A: Outcomes of nodular lymphocyte predominant Hodgkin's lymphoma (NLPHL) patients treated with R-CHOP [abstract]. Blood 2010, 116:2812.

48. Wang ES, Straus DJ, Teruya-Feldstein J, Qin J, Portlock C, Moskowitz C, Goy A, Hedrick E, Zelenetz AD, Noy A: Intensive chemotherapy with cyclophosphamide, doxorubicin, high-dose methotrexate/ifosfamide, etoposide, and high-dose cytarabine (CODOX-M/IVAC) for human immunodeficiency virus-associated Burkitt lymphoma. Cancer 2003, 98:1196-1205.

49. Landgren O, Algernon C, Axdorph U, Nilsson B, Wedelin C, Porwit-MacDonald A, Grimfors G, Björkholm M: Hodgkin's lymphoma in the elderly with special reference to type and intensity of chemotherapy in relation to prognosis. Haematologica 2003, 88:438-444.

50. Evens AM, Hutchings M, Diehl V: Treatment of Hodgkin lymphoma: the past, present, and future. Nat Clin Pract Oncol 2008, 5:543-556.

doi:10.1186/1756-0500-7-529

Cite this article as: Rota Scalabrini et al:: Complete remission of paraneoplastic vanishing bile duct syndrome after the successful treatment of Hodgkin's lymphoma: a case report and review of the literature. BMC Research Notes 2014 7:529.

\section{Submit your next manuscript to BioMed Central and take full advantage of:}

- Convenient online submission

- Thorough peer review

- No space constraints or color figure charges

- Immediate publication on acceptance

- Inclusion in PubMed, CAS, Scopus and Google Scholar

- Research which is freely available for redistribution 